\title{
Energia nuclear
}





\section{RESUMO}

Abordamos neste artigo algumas considerações importantes sobre o uso da energia nuclear. Respondemos questões gerais de interesse para o público como: o que é energia nuclear; por que usar urânio como combustível nos reatores; como avaliar a segurança da usinas no caso de abalos sísmicos; e qual a função da Agência Internacional de Energia Atômica.

Palavras-chave: energia nuclear, combustível, abalos sísmicos.

\section{ABSTRACT}

In this article we will address some important considerations on the use of nuclear energy. We will answers of general interest to the public, such as: What is nuclear energy? Why do reactors use uranium as fuel? How can we assess the safety in nuclear plants when there are seismic events? What is the role of the International Atomic Energy Agency?

Keywords: nuclear energy, fuel, seismic events. 


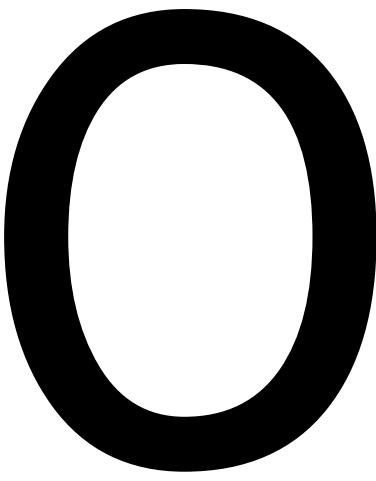

que é energia nuclear? Por que urânio? Como avaliar a segurança das usinas nucleares? (Efeitos sísmicos nas usinas). Qual a função da Agência Internacional de Energia Atômica?

As perguntas acima são frequentes e ficaram ainda mais relevantes depois dos acontecimentos sísmicos devastadores no início de 2011 no Japão. Vamos responder a elas de uma maneira simples e acessível ao público em geral. Há muito tempo, desde a época da Segunda Guerra Mundial, se debate a questão de uso pacífico da energia nuclear, a mesma gerada de forma incontrolável numa explosão nuclear. A palavra "controlável" acaba se tornando algo fundamental nas questões que estamos abordando. O físico italiano Enrico Fermi foi o primeiro a mostrar que o processo nuclear que gera a energia poderia ser controlado, e a partir de então foram construídos inúmeros reatores e usinas para gerar eletricidade a partir da fissão nuclear, mecanismo físico responsável pela geração da energia. A segurança dessas usinas, tanto no sentido de assegurar o seu funcionamento, quanto no de impedir o uso indevido dos produtos da combustão nuclear para fins militares, é de primordial importância. Elaboramos mais sobre essas questões em seguida.

\section{O QUEÉ ENERGIA NUCLEAR?}

Albert Einstein, num trabalho famosíssimo em 1905, sugeriu a equivalência entre matéria e energia através da sua fórmula mágica, $\mathrm{E}=\mathrm{mc}^{2}$, onde $m$ é a massa e $c$ a velocidade da luz no espaço livre cujo valor é 299.792.458 metros/segundo, que se aproxima de $3 \times 10^{8}$ metros/segundo. 
A partir dessa equação se imagina a transformação de uma quantidade mesmo pequena de massa $m$ em uma quantidade enorme de energia. Para dar um exemplo, considere uma massa de 1 grama que, por algum mecanismo, se transforma em energia. Usando a fórmula de Einstein se deduz que 1 grama de matéria poderia produzir 90 milhões de megawatts de potência de energia ( 1 megawatt = um milhão de joule por segundo), se transformada inteiramente.

O funcionamento da produção de energia nuclear se baseia nas considerações acima. Há dois modos de transformar matéria em energia: fusão e fissão. No primeiro processo se juntam dois núcleos para formar um núcleo maior. Para gerar energia nesse processoutilizam-se elementos leves como deutério (um núcleo de hidrogênio + um nêutron), trítio (núcleo de hidrogênio + um nêutron), etc.Juntando-se esses núcleos para produzir hélio, libera-se uma quantidade de energia muito grande devido à pequena diferença de massa entre a soma das massas dos núcleos originais e a massa do núcleo de hélio.

O outro processo, fissão, envolve a quebra de núcleos bem pesados ao serem bombardeados por nêutrons. O resultado da fissão é a produção de dois ou mais núcleos mais leves altamente radioativos. Há uma pequena diferença de massa entre o núcleo original e a soma das massas dos núcleos filhos. Essa diferença na massa aparece como energia, de acordo com a equação de Einstein. Assim se gera a energia nuclear! Fissiona-se um núcleo do átomo de urânio, e libera-se energia. É claro que tem que haver um mecanismo que torne o processo contínuo. Para isso a própria natureza dá sua contribuição no sentido de que, ao se fissionar o urânio, não somente se produz energia e núcleos filhos, mas também mais nêutrons, que por sua vez induzem a fissão de mais núcleos, e o processo se repete em princípio sem controle. O resultado desse processo é uma reação em cadeia fora de controle, que é usada para fabricar bombas atômicas. A energia nuclear usada para fins pacíficos é produzida em reatores nucleares onde se controla a reação em cadeia. Tal feito

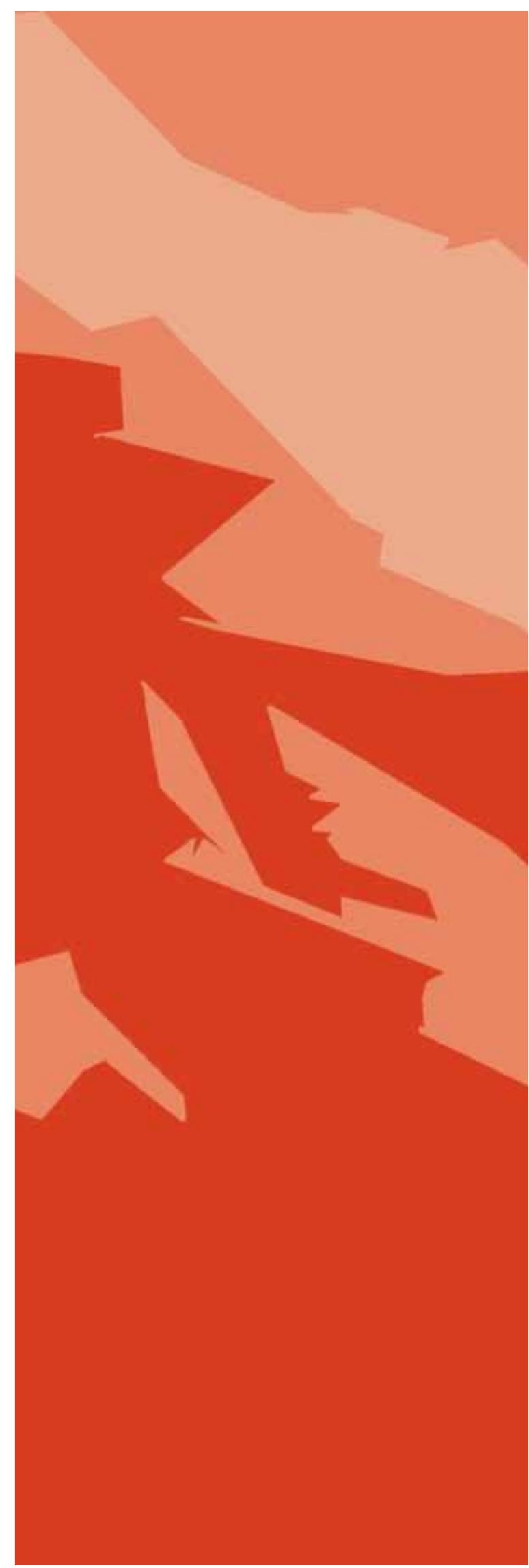


é realizado por meio de moderadores que absorvem uma parte dos nêutrons produzidos no processo de fissão. A estrutura básica de reatores nucleares é relativamente simples: barras de combustível (urânio ligeiramente enriquecido) + barras de moderadores (grafite) + refrigerador (água). A energia liberada pela fissão acaba aquecendo a água, que, ao produzir vapor, opera as turbinas para produzir eletricidade.

\section{POR QUE URÂNIO?}

É utilizado como combustível de fissão um elemento químico cujo núcleo tem a propriedade de altíssima probabilidade de captura de nêutrons. Há vários elementos que têm essa característica, mas o campeão deles é o urânio.

O princípio físico da energia nuclear é, portanto, simples. O desafio maior na construção de usinas é um problema de engenharia. Preparar o combustível é problema em química: há minério de urânio natural que contém três isótopos, U238, U235 e U234. Os últimos dois são isótopos radioativos de longa vida (0,1-0,2 milhão de anos). O U238 tem uma concentração da ordem de $99,26 \%$ e não fissiona ao ser bombardeado por nêutrons térmicos (lentos).

O segundo e o terceiro são os únicos que têm essa propriedade (de fato, U233, ao ser bombardeado por nêutrons, se transforma em U234 num estado quântico excitado que fissiona). A porcentagem de U235 no urânio natural é muito reduzida, em torno de 0,72\%, enquanto a do último é 0,0054\%. Por issoé preciso “enriquecer” o urânio para aumentar a porcentagem desses isótopos. Urânio enriquecido até 5\% quer dizer que a porcentagem de U235 é artificialmente aumentada para 5\% no minério. Esse material processado é o usado em reatores nucleares. Enriquecimento maior implica um potencial uso em reatores menores, que são montados em submarinos, e com valores muito altos, como $80 \%$ a $90 \%$, é possível fabricar artefatos nucleares explosivos. Por isso há grande preocupação em fiscalizar o 
processo de enriquecimento para ter certeza que o uso seja para fins pacíficos.

Salientamos ainda que mesmo o uso nos reatores nucleares do urânio enriquecido até $5 \%$ poderia eventualmente levar, após o processo da produção da energia, a um material potencialmente bélico. $\mathrm{O}$ isótopo benigno U238 se transforma em U239 ao absorverum nêutron. Esse novo isótopo não é estável (sobrevive apenas 23 minutos), e decai para o núcleo de plutônio Pu239, que tem uma vida bem mais longa (24.110 anos). Esse núcleo é também fissionável e poderia ser usado para fabricar bombas nucleares (as bombas usadas no Japão no fim da Segunda Guerra Mundial foram de U235 em Hiroshima e de Pu239 em Nagasaki).

É uma questão importante na segurança nuclear a fiscalização da quantidade de Pu239 produzido após um longo uso das usinas, e o modo como esse produto (que é nocivo tanto nuclear como quimicamente) é coletado e eventualmente destruído. Salientamos ainda que o conhecido "lixo nuclear" não contém somente o plutônio, mas outros isótopos produzidos ao se fissionar o núcleo de U235. São produtos "industriais" mais alarmantes no sentido de que eles são altamente radioativos e com meia-vida suficientemente curta (algumas décadas) para afetar a saúde humana. Como queimar ou se livrar desses produtos é algo que motiva inúmeras discussões. Uma das técnicas usadas é enterrá-los em locais afastados. Uma outra, mais eficiente, porém cara, é literalmente queimá-los usando aceleradores de partículas (prótons). Essa técnica prevê construir tais aceleradores num local próximo às usinas. Devido ao alto custo (mais que 1 bilhão de dólares) é somente usada em alguns países.

Pode-se perguntar se há outro meio de produzir energia nuclear de fissão que não deixe resíduos radioativos. De fato há: é a utilização de U233, que não existe na natureza como combustível. Pode-se produzi-lo através da captura de nêutrons pelo abundante elemento Th232 (tório). Ao absorver um nêutron, esse elemento se transforma em U233, que por sua vez pode capturar um nêutron e, fissionado, produzir energia e mais nêutrons, e o ciclo se repete. Essa técnica não produz plutônio e, portanto, é potencialmente mais segura. Vários fatores, que variam desde engenharia até custo econômico, tornaram esse projeto menos popular. Mesmo assim, países onde há grandes depósitos de tório e não tanto urânio, como China e Índia, têm em andamento projetos de construção de usinas movidas a tório. No Brasil, há grande quantidade de minério de urânio e evidentemente as usinas de Angra são de urânio.

\section{COMO AVALIAR A SEGURANÇA DAS USINAS NUCLEARES? (EFEITOS SÍSMICOS NAS USINAS)}

Em países com atividade sísmica apreciável, torna-se importante a questão de segurança da estrutura e construção das usinas nucleares com relação a possíveis abalos. Especial cuidado é tomado para garantir a manutenção da integridade dessas estruturas. No Japão, onde esses abalos são frequentes, todos os prédios de grande porte são construídos sobre molas, que amortecem as vibrações da terra. Não há evidências de que os recentes acontecimentos no Japão, que abalaram o país e colocaram mais uma vez a segurança das usinas nucleares em xeque, resultaram em estragos estruturais devido ao terremoto. Foi o tsunami que acompanhou o terremoto que gerou os grandes problemas em virtude da imensa quantidade de água que inundou uma grande parte da região costeira e afetou o funcionamento das usinas.

Não houve o meltdown que marcou para sempre Chernobyl. Meltdown ou fusão refere-se ao processo em que o calor transportado pela água fica inferior ao calor gerado nas barras de combustível nuclear de tal maneira que este último acaba por fundir. Esse dano à estrutura do componente fissionável representa um perigo imenso que tem que ser evitado. Na usina de Chernobyl, aconteceu exatamente isso, 
o que levou a usina a sofrer grandes danos com vazamento letal de material radioativo. Mas o acidente de Chernobyl não ocorreu como consequência de abalo sísmico, mas devido a um defeito na construção da usina. Mesmo assim, todo cuidado é necessário para garantir que, no caso de atividades sísmicas de grande porte, não ocorram abalos na estrutura da usina. No caso das usinas de Angra dos Reis, seria de grande valia que a prefeitura da cidade instalasse um sistema de alerta à população no caso de qualquer problema que pudesse afetar o funcionamento dos reatores.

\section{REATOR NATURAL?}

É incrível que a própria natureza tenha “fabricado" o primeiro reator! No Gabão, país africano, na região de Oklo, há evidências claras da existência, no passado distante, de um acúmulo de urânio naturalmente enriquecido até chegar à massa crítica que iniciou uma reação em cadeia. Essa reação se manteve muito tempo até se extinguir. Sua descoberta foi feita pelo francês Francis Perrin em 1972. O que se encontrou ao se analisar a composição do minério de urânio foi uma porcentagem menor de U235, de $0,717 \%$, comparada com o usual $0,72 \%$. Essa diferença significativa somente pode ser explicada pelo esgotamento devido à fissão (o mesmo efeito acontece em reatores convencionais: a porcentagem de U235 é gradualmente diminuída até que o reator pare de funcionar depois de alguns anos). Esse reator deveria ter começado a funcionar aproximadamente 1,8 bilhão de anos atrás, durando algumas centenas de milhares de anos. Vários outros sítios foram achados em Oklo com concentração de U235 de apenas $0,44 \%$, indicando claramente a ocorrência de reação de fissão muitos anos atrás. Como começou esse reator? Há evidências de que a água inundou os depósitos de urânio em Oklo, agindo como moderador e refrigerador para permitir o início e a continuação da reação de fissão em cadeia. A água evaporou por causa do calor advindo da reação nuclear, mas mais água voltou a inundar os depósitos de urânio, e assim ocorreu o reator nuclear natural na África!

\section{QUAL A FUNÇÃO DA AGÊNCIA INTERNACIONAL DE ENERGIA ATÔMICA?}

A Agência Internacional de Energia Atômica (AIEA, sigla em inglês IAEA) foi estabelecida nos anos 50 para, durante o período da Guerra Fria, fiscalizar o processamento de urânio e garantir que o plutônio produzido nas usinas não tivesse finalidade militar. Há inúmeros centros de vigilância ligados à IAEA cuja função é fornecer informações e recomendações sobre como armazenar o lixo nuclear produzido, e ajudar na coleta de plutônio para poder descartá-lo. Há vários organismos ligados à IAEA que trabalham nas várias facetas de coleta de informações nucleares usadas para fins pacíficos. 